\title{
Hidden: How general studies of shopping centres mask store differences
}

Received (in revised form): 11 January 2008

\section{David M. Ambrose}

received his doctorate from the George Washington University (US) and has been both a faculty member in marketing and entrepreneurship and a consultant to a broad variety of business organisations. He has been a professor in the Department of Marketing and Management at the University of Nebraska at Omaha for more than 30 years.

\section{John R. Anstey}

received his doctorate from the University of Arkansas (US) and has been actively engaged as a faculty member of management and organisation. He has been engaged in the academic preparation of advanced secondary students oriented toward a university education for more than 20 years. He has been a professor in the Department of Marketing and Management at the University of Nebraska at Omaha for more than 30 years.

\section{Anna V. Vygodina}

received her doctorate from the University of Nebraska, Lincoln (US) and has been intensely involved as a faculty member of finance in the academic development of courses and engaging students in the modern financial world. She is currently a professor of finance on the faculty at the California State University, Sacramento (US).

\begin{abstract}
Numerous studies that are conducted to provide an understanding of the attractiveness and conditions of shopping centres consider these complexes as composite entities. As a result, the studies measure and illustrate the overall shopping centres and not the individual retailers. The problem with this approach is the profiles of the individual stores may differ significantly from the aggregate profile of the overall shopping centre. The authors conducted a consumer assessment of the market conditions of a composite retail sector in Blair, Nebraska (US). The issues that composed the study were very similar to those of other contemporary market analyses. In the design of this study, the respondents, however, provide assessments and perceptions of the individual retailers of the shopping district. Therein, the study data profiled both the individual stores and compares them to the assessments as a composite of all stores. The intent of this paper is to sharpen the research methodologies addressing shopping centres and to distinguish the findings of overall assessments from the findings of store-specific assessments.
\end{abstract}

David M. Ambrose College of Business Administration University of Nebraska Omaha, Nebraska 68154, USA

Tel: +14023302776

Fax: +14025542010

E-mail:ambrose1@cox.net

\section{Keywords:}

shopping centres, retailer evaluations, consumer perceptions

Journal of Retail and Leisure Property (2008) 7, 95-102. doi:10.1057/rlp.2008.2; published online 5 March 2008 


\section{INTRODUCTION}

The composite profile provided a general assessment, one that is typical in shopping centre analyses. But, when these summary response values were compared to those values for the individual retail establishments, nearly half of the individual retail profiles differed significantly from the composite of all retailers. The researchers concluded, therefore, that studies that address only composite issues might obliterate the uniqueness of individual retail members and thereby eliminate the possibility of focused strategic planning for member retailers.

The development of precise information about the perceptions and performances of a retail sector is a critical element in shopping centre management. Much of the research in assessing shopping centres considers the retail environment as a single entity. The retail customers, when describing their experiences or attitudes toward retailing in a shopping centre, frame these descriptions as encompassing experiences with the individual retailers in the shopping complex.

Our argument is that shopping centre studies are not relevant to the individual retailer and therefore can be more confusing than illuminating.

Premised upon research that assessed retailers of a shopping district of a community, this paper illustrates with measured results that a composite assessment may differ significantly from the assessment of the individual retailers. The emphasis of this paper is to avoid conducting aggregated research intended to profile the character of a local retail sector. From our data, we find a composite assessment can mask variances of individual retailer performances.

\section{RETAIL SECTOR PROFILES}

The typical shopping centre assessment addresses concepts of satisfaction levels, adequacy of parking, selection of merchandise, and even if the customers find the complex a pleasant environment and shopping experience. Many of these studies are not store-specific but general to the entire retail sector. The studies look at retailing in general and not retailing as performed by the individual member retailer.

The true nature of the retail sector of a shopping centre, however, is determined by the behaviours of the individual retailers. When a study is done that measures the composite profile of the retail sector, the respondents assess the composite according to their retail experiences with the individual retail stores. Therefore, the surveys reflect the customers' shopping perceptions of specific stores and not just the evaluation of the shopping centre in general. Therein, the assessment of the shopping centre is a composite reflection of the retail performances of the individual stores.

\section{RETAIL-ORIENTED ASSESSMENTS}

Retail studies that are specifically intended to assist strategic planning must measure the behaviours of the individual retail stores. The importance of the retail studies to growth and business retention is 
embedded in the discoveries of unsatisfactory and below standard behaviours of the individual retailers. It is impossible to identify those specific performances from generalised market-wide studies.

Shopping centre management must be cognizant of retailing practices of the specific stores. Retailer behaviour may be negatively impacting the consumers' shopping experience. The quality of customer services certainly affects the evaluations of respondents. Store merchandising methods can also make it extremely difficult for shoppers to make informed selections. Also, inadequate store lighting, and objectionable odours among other issues are all detrimental to the maintenance of strong patronage. These deviations from generally accepted practices affect the shopping experiences of the public.

In the extreme situations, a poorly lighted store may constitute a hazardous environment for both customers and employees and be in violation of occupancy codes of the local government. Odours that emanate from improper trash handling and disposal likewise could be addressed by health officials. But, enforcement officials are reluctant to cite cosmetic and lesser infractions that do not pose a measurable risk. These conditions, however, do detract from the attractiveness of the store, and the shopping centre.

\section{RETAILING EFFECTS ON THE SHOPPING CENTRE IMAGE}

Given the prior discussion, it is apparent that the behaviours of the individual retailers determine the composite image and attractiveness of the retail sector. In this regard, a general shopping centre image analysis may be interesting but it does not provide the details to adjust the deficiencies or to further enhance the strengths. That requires an understanding and an identity of the individual retailers.

It can be argued that a comprehensive retail assessment is a shopping centre's best method of understanding shoppers' perceptions and evaluations of the retail sector of the total shopping centre. Holes in merchandise lines and services can be identified. The respondents may identify inappropriate performances of existing retailers. Likewise, a study that evaluates the retail performance can be used by the retailers to institute changes to remove problem areas. The effectiveness of these studies, however, requires the individual store management to introspectively identify with the low performances reported. That requirement is contrary to normal management behaviour.

Further, a difficulty with general retail studies is the obliteration of the extreme behaviours, both positive and negative, of the retailers. The use of the aggregation of data blends out these extremes and presents averages - where the behaviours are average and there is no identification of the points of poor performance or the highlights of strength. While the inclusion of standard deviations would illustrate the presence of extremes, it is questionable whether store managers would understand and appreciate the concepts of the calculations of standard deviations. 


\section{STORE-SPECIFIC ASSESSMENTS COMPARED TO COMPOSITE ANALYSES}

In conducting the research to determine the comparison, the researchers used a study questionnaire to gather the assessments of the residents of Blair, Nebraska. There were eight retail assessment questions regarding 12 stores. There were 103 respondents to the study as illustrated in Table 1. Since respondents were asked to evaluate only those stores with which they were familiar, the actual number of evaluations per store was less than 103.

The summations in Table 1 are typical of shopping centre store surveys. Respondents are asked to evaluate 'in general' factors, similar to the eight profile factors used in the Blair study. The initial review of the data included the summations for 'All stores', the mean values and standard deviation values. If the Blair study had been typical and had not identified the individual stores, the first column of data would have been the only data presented.

Note, however, the first column of data in this research is the arithmetic summation of the evaluations of the individual stores and not a response to a question about the general attributes of the retail environment. This general assessment was obtained as the summation of experiences of individual stores and therefore these data represent the composite market profile of these 12 retailers.

In using just the first column of data (All stores) from Table 1, we would be interpreting these values to develop an understanding of the conditions of the general retail environment, as defined by the 12 stores in the study.

There were 103 respondents to the study. Because of the summation of responses in the 'All stores' category, the number replying as All stores is considerably higher than the 103 respondents of the study. The mean values of assessment for each store and each issue are developed from the responses to that individual question using a four-point scale of agreement/satisfaction, four being the highest. The values for All Stores were the summations of the responses for each of the individual stores, the row values.

There are several interpretations that can be derived from these data. (The assessment value is illustrated by the mean value of each store, each issue.) The degree of dispersion is measured by the standard deviation. The composite of the market of the 12 stores is reflected in the mean values of the All stores column.

The question then becomes whether the All stores value can be used as a representation of the individual stores. In reflecting on the prior discussion, many retail analyses do not measure the factors according to the individual stores but ask about all stores in general. Does a retail sector analysis with that survey design properly reflect the characteristics of the individual stores that compose the shopping centre? In other words, does the value of 3.80 of All stores for the issue 'I know about the store' properly reflect the knowledge of all 12 of the stores in the study? The differences between the individual store responses and the 3.80 value are clearly evident by merely comparing the 3.80 to the other values of that row. There can, however, be some differences between the All stores 
How general studies of shopping centres mask store differences 荄

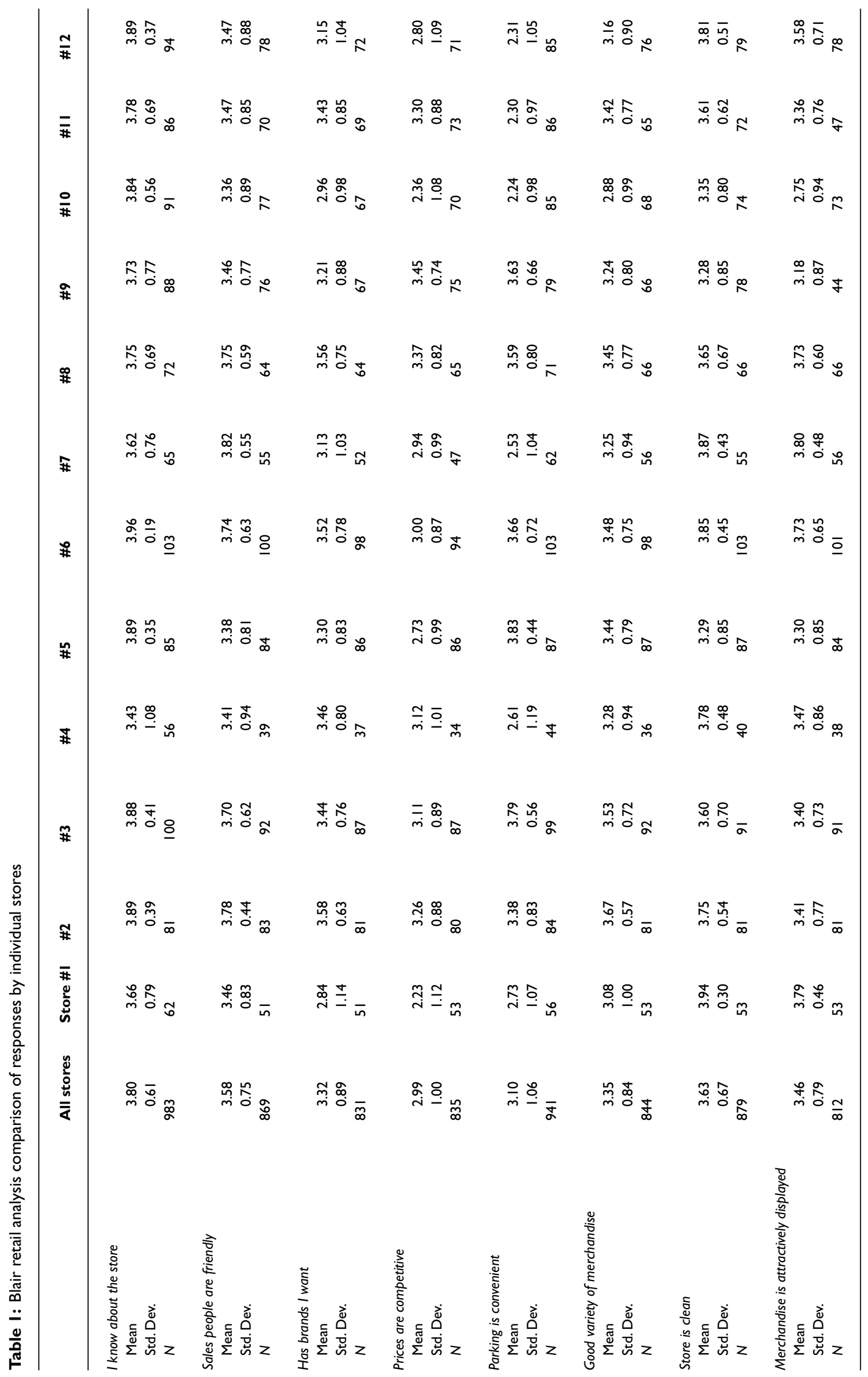


value and the individual store value and yet the differences are not statistically significant. Only by statistically testing these individual mean values to those mean values of the composite for All stores can that determination be made.

In Table 2, the testing of differences between All stores and the individual stores is reflected. The researchers used the generally recognised and accepted 'Difference of Means' test for this purpose.

In the difference of means testing, two standard deviations of difference at 95 per cent are \pm 1.96 . In interpreting this table, all measures that exceed the \pm 1.96 are considered as being statistically different. These are indicated in the bold type values.

It is important to note that in this research, parking was noted as being significantly different for every store. This is noted in the row of values on 'Parking is convenient'. This indicates the perceptions of respondents differ for all 12 stores when assessing the convenience of parking. Because this study used individual stores of a 'shopping district' rather than a shopping centre, the parking relative to each store could be significantly different, and apparently was according to the study results. This particular assessment does reflect the actual condition as it relates to each individual retailer. Also, Store \#10, as an extreme, has seven out of the eight values differing significantly from the composite average values for All stores. For store \#10, the respondents' assessments of the factors of evaluation were greatly different than the assessment for the average of All stores.

It should also be noted, that of the 96 different store assessments (12 stores, eight issues), that 43 of these were significantly different for the individual store when compared to the average for All stores. If there were only several differences, a composite average is sufficiently representative of All stores of a retail sector. When 44.8 per cent of the store values differ significantly, we must, however, be attentive to the assessments of the individual stores and reject the composite average as not being a reliable profile of the shopping centre.

\section{STUDY IMPLICATIONS}

The main research finding is shopping centre studies that generalise can obliterate a number of significant differences that exist with the individual retail stores. The composite (or 'averaging') that respondents provide in making an assessment of the shopping centre as a total entity differed significantly in nearly half the cases of this study. As a result, a composite analysis may be misleading and obliterate the actual operating conditions of the member retailers.

In this study, the average responses resulted in nearly half of the store specific assessments being significantly different from the composite. We questioned the high proportion of differences and considered the effects if the averages for All stores had been higher or lower. In our review of this proposition, we found that changing the All stores average arbitrarily to higher and lower levels changed the number of significant specific store differences slightly and if the averages were changed greatly, the number of differences actually increased. In other words, the differences 


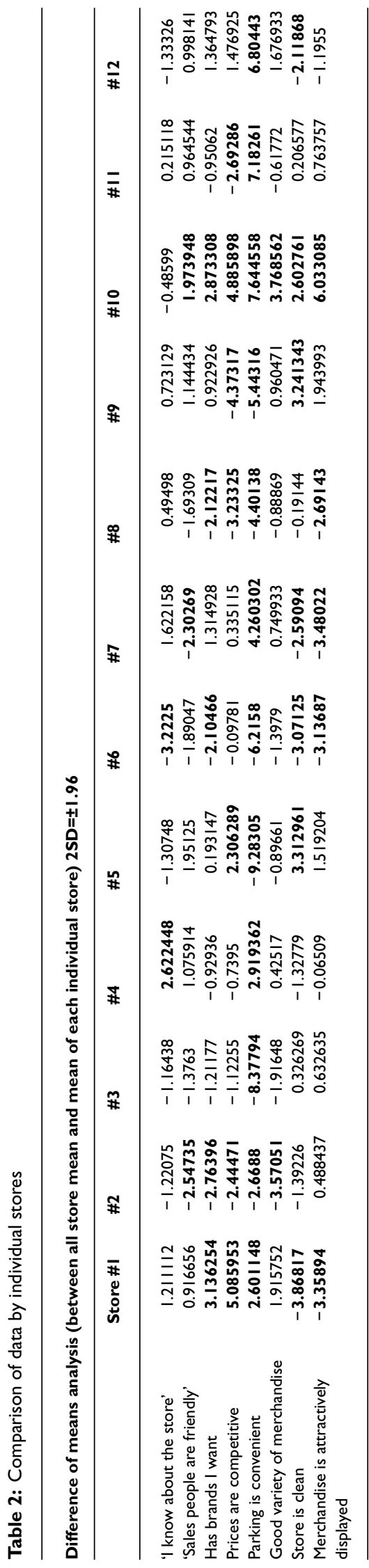


constituting 44.8 per cent of the cases were related to the dispersion of responses of the individual stores and not caused by the resulting average of All stores.

Our belief is the conditions and the resulting research findings of this study are not singular to Blair. In fact, we believe that the composition of stores and their individual operating differences are more likely typical of retail behaviour that would be found in shopping centres in general. Therefore, the general findings of significant differences of individual store assessments would be reflective of the findings of other shopping centre studies if this study methodology were to be replicated.

It is impossible to know whether differences exist unless a retailerspecific study is conducted. In a general shopping centre study, wide dispersion of responses, as illustrated by the standard deviation, would indicate levels of difference between the individual stores. But, even this cannot be ascertained from the composite assessments - whether those dispersions relate to differences at the individual store level or whether there was general disagreement for All stores. And, the answer to that question could not be developed without conducting store-specific assessments.

\section{SUMMATIONS}

The profile of a shopping centre is determined in large part by the behaviours of the individual retailers. While a general composite assessment of the shopping centre may provide an overall measure of the retailing environment, it does not provide a detailed assessment of the individual retailer behaviour and conditions. Studies that assess specific store behaviours are required.

Shopping centre studies that ask respondents to assess the behaviours of all retailers as a single question potentially obliterate the actual uniqueness and differences that exist between the specific and individual stores. Because these summary assessments may be masking the extremes of retail behaviour, it is impossible for shopping centre management to address and realign retailing practices except in a very general manner. And, these corrections would be unfair and inappropriate to bring to the attention of some of the retailers.

The only means to correctly assess retail behaviour as it affects the composite shopping centre is through store-specific studies. There is no method by which these study requirements can be circumvented. While possibly not all retail shopping centre will have significant differences, that is unknown until store-specific assessment are conducted. Strong shopping centre management is dependent upon those store-specific assessments. 